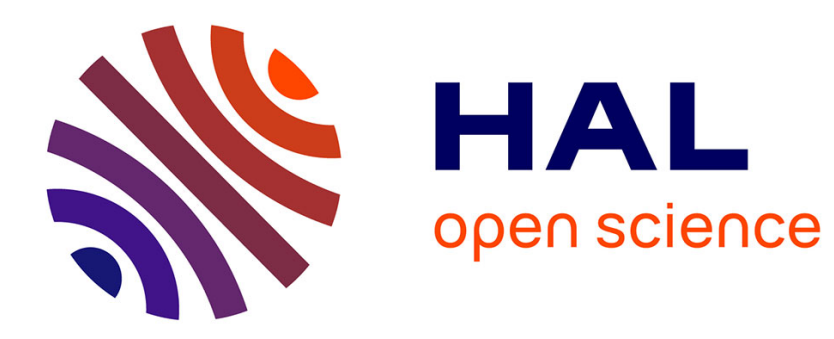

\title{
Models of donor impurity compensation in cadmium telluride
}

\author{
Y. Marfaing
}

\section{To cite this version:}

Y. Marfaing. Models of donor impurity compensation in cadmium telluride. Revue de Physique Appliquée, 1977, 12 (2), pp.211-217. 10.1051/rphysap:01977001202021100 . jpa-00244145

\section{HAL Id: jpa-00244145 https://hal.science/jpa-00244145}

Submitted on 1 Jan 1977

HAL is a multi-disciplinary open access archive for the deposit and dissemination of scientific research documents, whether they are published or not. The documents may come from teaching and research institutions in France or abroad, or from public or private research centers.
L'archive ouverte pluridisciplinaire HAL, est destinée au dépôt et à la diffusion de documents scientifiques de niveau recherche, publiés ou non, émanant des établissements d'enseignement et de recherche français ou étrangers, des laboratoires publics ou privés. 


\title{
MODELS OF DONOR IMPURITY COMPENSATION IN CADMIUM TELLURIDE
}

\author{
Y. MARFAING \\ Laboratoire de Physique des Solides, C. N. R. S., 92190 Bellevue, France
}

\begin{abstract}
Résumé. - On présente une revue des divers modèles proposés pour expliquer la compensation électrique des donneurs dans CdTe. Ces modèles diffèrent par la force des interactions entre impuretés et lacunes de cadmium : aucune interaction entre donneurs et défauts chargés; formation de complexes par association entre défauts et impuretés ; compensation chimique entre donneurs et défauts natifs.

Ces analyses supposent une concentration élevée en lacunes ionisées. Les résultats de mesures à haute température sont discutés qui fixent certaines limites à la concentration en lacunes ionisées, sous des conditions d'équilibre spécifiées. A partir de ces valeurs, il apparaît difficile de rendre compte de la compensation de donneurs dans le domaine de $10^{17} \mathrm{~cm}^{-3}$. Une hypothèse est avancée selon laquelle des lacunes neutres en concentration élevée sont présentes. Le processus de compensation est décrit comme une interaction donneur-lacune neutre, ces complexes étant stabilisés par piégeage d'électrons.

Selon ce point de vue, la perfection électronique des cristaux de CdTe actuels est limitée par la teneur en impuretés résiduelles.
\end{abstract}

\begin{abstract}
A review is presented of the various models proposed to explain electric compensation of donors in CdTe. These models differ by the strength of interaction between impurities and cadmium vacancies : non interacting donor ions and charged defects; formation of complexes by association of defects and impurities; chemical compensation between donors and native defects.

These analysis postulate the presence of a large number of ionized free vacancies. Results of high temperature measurements are discussed which set certain limits to the concentration of ionized vacancies under specified conditions. Starting from these values it appears difficult to account for compensation of donor impurities in the range $10^{17} \mathrm{~cm}^{-3}$. A tentative model is then presented which assumes the existence of neutral cadmium vacancies in a large concentration and describes the compensation process by a donor-neutral vacancy interaction, such complexes being stabilized by electron trapping.

From this point of view, the electronic perfection of presently grown CdTe is limited by the residual impurities content.
\end{abstract}

1. Introduction. - Semi-insulating CdTe is usually obtained by impurity compensation : in the accepted scheme, a certain amount of donor impurities is introduced in the material in order to compensate acceptor native defects, which are generally thought to be cadmium vacancies.

From this viewpoint the quality of semi-insulating $\mathrm{CdTe}$, in terms of concentration of trapping centers, recombination centers, is limited by the concentration of ionized native defects, which require impurities to compensate them. However high resistivity material has also been obtained without intentional doping.

Thus it seems useful to review and reexamine the compensation models in order to test the validity of their basic implications. Clearly, the central problem is the problem of interaction between impurities and native defects. The various models differ by the way they describe this interaction.

Furthermore these models make use of several quantities such as energies of formation and ionization of native defects which are far to be accurately known.
However, from simple experimental results, relations between these quantities can be established which help to delimit the domain of uncertainty.

Then a new and tentative viewpoint will be introduced which emphasizes the role of neutral cadmium vacancies in the formation of donor-defect complexes. Consequences on material characterisation will by finally discussed.

2. Models of impurity compensation. - 2.1 COMPENSATION BETWEEN ISOLATED IONIZED SPECIES. This is the simple model used by De Nobel [1], reviewed by Kroger [2] and which is at the basis of Mandel analysis [3]. The central relation is the neutrality equation

$$
n-p=\left[D^{\bullet}\right]-\left[V_{\text {Cd }}^{\prime}\right]-2\left[V_{\text {Cd }}^{\prime \prime}\right]
$$

$n$ and $p$ are free electron and hole concentrations. [ $\left.D^{\circ}\right]$, $\left[V_{\mathrm{Cd}}^{\prime}\right]$ and $\left[V_{\mathrm{Cd}}^{\prime \prime}\right]$ denote according to Kroger symbols, concentration of ionized donors, singly and doubly ionized cadmium vacancies respectively. The con- 
centration of neutral native defects is determined by equilibrium with the vapour phase

$$
\mathrm{Cd}_{\mathrm{Cd}} \rightleftarrows \mathrm{Cd}(g)+V_{\mathrm{Cd}}^{x} .
$$

The mass action law gives

$$
\left[V_{\mathrm{Cd}}^{x}\right]=\frac{K_{\mathrm{v}}}{p_{\mathrm{Cd}}}=\frac{\exp \left[-\frac{\Delta H_{\mathrm{v}}}{k T}+\frac{\Delta S_{\mathrm{v}}}{k}\right]}{p_{\mathrm{Cd}}} .
$$

$\Delta S_{\mathrm{v}}, \Delta H_{\mathrm{v}}$ excess entropy, excess enthalpy of neutral vacancy formation is the first set of parameters. They are not directly determined but only through the electrical activity of ionized species $V_{\mathrm{Cd}_{d}}^{\prime}$ and $V_{\mathrm{Cd}}^{\prime \prime}$.

These ionized species are related to the neutral one by two other mass action laws

$$
\begin{aligned}
& \frac{\left[V_{\mathrm{Cd}}^{\prime}\right] p}{\left[V_{\mathrm{Cd}}^{x}\right] N_{\mathrm{v}}}=K_{1}=\exp \frac{E_{\mathrm{v}}-E_{1}}{k T} \\
& \frac{\left[V_{\mathrm{Cd}}^{\prime}\right] p}{\left[V_{\mathrm{Cd}}^{\prime}\right] N_{\mathrm{v}}}=K_{2}=\exp \frac{E_{\mathrm{v}}-E_{2}}{k T}
\end{aligned}
$$

$N_{\mathrm{v}}$ is the valence band density of states. $E_{1}, E_{2}$ are the vacancy electronic levels in the state of ionization single and double respectively. This is the second set of parameters. In principle $E_{1}, E_{2}$ can be determined by standard electrical and optical methods. However no convincing correlation has been obtained so far and this is the subject of many speculations. Equilibrium between electrons and holes gives the $n p$ product

$$
n p=K_{0}=N_{\mathrm{c}} N_{\mathrm{v}} \exp \left(-\frac{E_{\mathrm{g}}}{k T}\right)
$$

$N_{\mathrm{c}}$ is the conduction band density of states. $E_{\mathrm{g}}$ is the energy band gap.

The neutrality equation can now be written as

$$
\begin{aligned}
n-\frac{K_{0}}{n}=\left[D^{\bullet}\right]-n & \cdot \frac{K_{1}}{K_{0}} \cdot N_{\mathrm{v}} \cdot \frac{K_{\mathrm{v}}}{p_{\mathrm{Cd}}} \times \\
& \times\left(1+2 n \cdot \frac{K_{2}}{K_{0}} \cdot N_{\mathrm{v}}\right) .
\end{aligned}
$$

When applied to the high temperature equilibrium this equation allows one to calculate the electronic concentration $n$ as a function of the vapour phase pressure $p_{\mathrm{Cd}}$ and the ionized donor concentration [ $\left.D^{\circ}\right]$. The latter is equal to the total donor concentration for shallow donor levels.

Then the concentration of ionized species [ $\left.V_{\mathrm{Cd}}^{\prime}\right]$ $\left[V_{\mathrm{Cd}}^{\prime \prime}\right]$ are computed from eqs (4), (5) and (6) so that the total concentration of cadmium vacancies introduced in the crystal can be determined :

$$
\left[V_{\mathrm{Cd}}\right]=\left[V_{\mathrm{Cd}}^{x}\right]+\left[V_{\mathrm{Cd}}^{\prime}\right]+\left[V_{\mathrm{Cd}}^{\prime \prime}\right] .
$$

Compensation is observed at room temperature, after a quenching which is supposed to keep unchanged the total concentration $\left[V_{C d}\right]$, and can be discussed as follows.
Let us consider the energy diagram of figure 1, such as assumed by Kröger [2].

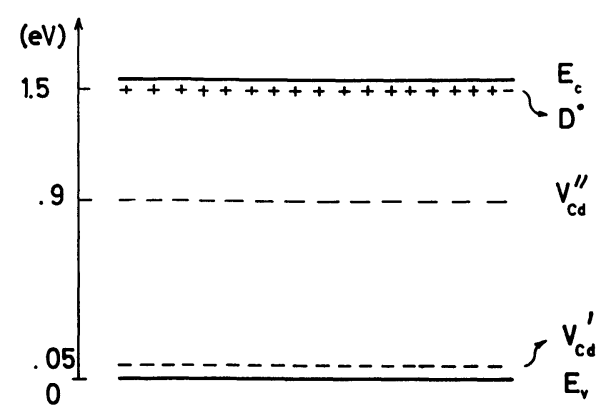

FIG. 1. - Energy level diagram of CdTe as assumed by Kröger [2].

A high resistivity state will be reached if the Fermi level is stabilized near the midgap. This occurs when the first ionization level $E_{1}$ is filled by donor electrons and the second level $E_{2}$ is only partially filled. Th condition ofr compensation is

$$
\left[V_{\mathrm{Cd}}\right] \leqslant\left[D^{\bullet}\right] \leqslant 2\left[V_{\mathrm{Cd}}\right]
$$

and is summarized on figure 2 .

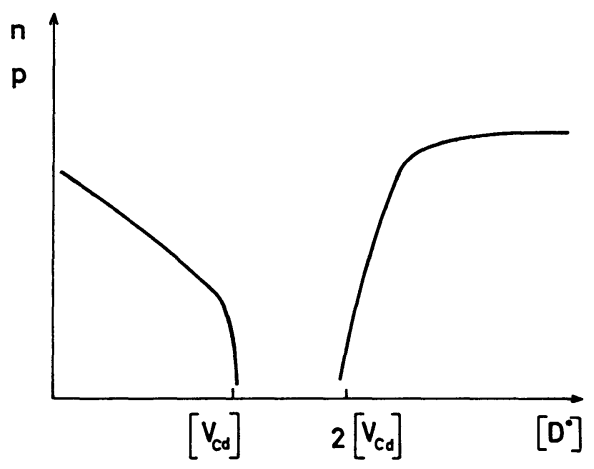

FIG. 2. - Range of donor compensation in the isolated species model.

We recall that $\left[V_{\mathrm{Cd}}\right]$ is a function of $\left[D^{\bullet}\right]$ from the high temperature equilibrium, so that the last relations are self consistent ones This analysis makes to appear a limited range of donor concentration in which compensation occurs and the existence of a p-type conductivity, due to vacancy ionization, at low donor concentration.

As we shall see latter, the correlation between the observed p-type conductivity and vacancy ionization is questionnable.

Furthermore undoped highly purified p type crystals do not show any evidence of the $E_{1}$ level at $E_{\mathrm{v}}+0.05 \mathrm{eV}$ as seen from photoluminescence measurements [4].

This casts some doubt on the energy level scheme of figure 1.

2.2 Formation of COMPLEXES. - A comprehensive analysis including the complex formation was recently 
given by Chern and al. [5] Such a model was also used by Hoschl [6].

Electrostatic interaction between ionized donors and ionized vacancies can lead to the formation of closed pairs or complexes according to the quasi equilibrium relation :

$$
V_{\mathrm{Cd}^{\prime}}^{\prime \prime}+D^{\cdot} \rightleftarrows\left(V_{\mathrm{Cd}} D\right)^{\prime}
$$

This new ionized species enters the neutrality equation :

$n-p=\left[D^{\bullet}\right]-\left[V_{\mathrm{Cd}}^{\prime}\right]-2\left[V_{\mathrm{Cd}}^{\prime \prime}\right]-\left[V_{\mathrm{Cd}} D\right]^{\prime}$.

Two additionnal mass action laws can be written

$$
\begin{gathered}
\frac{\left[V_{\mathrm{Cd}} D\right]^{\prime}}{\left[V_{\mathrm{Cd}}^{\prime \prime}\right]\left[D^{\circ}\right]}=K_{\mathrm{p}}=\exp -\left[\frac{\Delta H_{\mathrm{p}}}{k T}-\frac{\Delta S_{\mathrm{p}}}{k}\right] \\
\frac{\left[V_{\mathrm{Cd}} D\right]^{\prime}}{\left[V_{\mathrm{Cd}} D\right]^{x}} \frac{p}{N_{\mathrm{v}}}=K_{3}=\exp \frac{E_{\mathrm{v}}-E_{3}}{k T} .
\end{gathered}
$$

Three new parameters are introduced : $\Delta S_{\mathrm{p}}, \Delta H_{\mathrm{p}}$, the excess entropy and enthalpy of pairing and $E_{3}$ the energy level of the acceptor complex.

As before, the high temperature equilibrium is first considered which leads to determine the total defect concentrations $\left[V_{\mathrm{Cd}}\right]$ and $\left[V_{\mathrm{Cd}} D\right]$ introduced in the crystal for given values of temperature, pressure and donor concentration.

Then the occurence of compensation at room temperature can be discussed from the energy level diagram depicted on figure 3 .

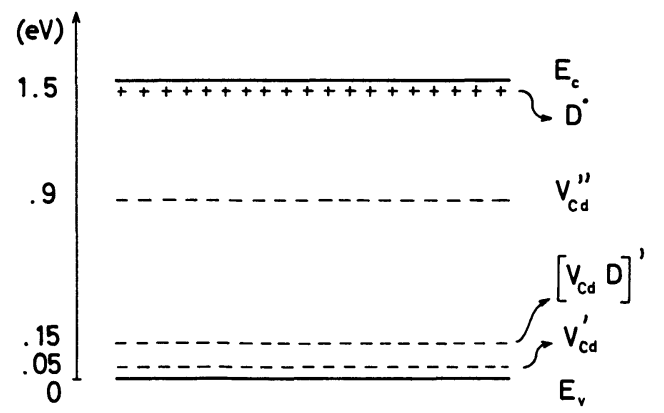

Fig. 3. - Energy level diagram of $\mathrm{CdTe}$, including donorvacancy complexes, as assumed by Chern [5].

A high resistivity state is obtained after filling of the level associated to $V_{\mathrm{Cd}}^{\prime}$ and $\left(V_{\mathrm{Cd}} \mathrm{D}\right)^{\prime}$ which leads to the condition

$$
\left[V_{\mathrm{Cd}}\right]+\left[V_{\mathrm{Cd}} D\right]<\left[D^{\circ}\right]<2\left[V_{\mathrm{Cd}}\right]+\left[V_{\mathrm{Cd}} D\right] .
$$

The total number of donor atoms is

$$
[D]_{\mathrm{T}}=\left[D^{*}\right]+\left[V_{\mathrm{Cd}} D\right]
$$

which allows to write

$$
\left[V_{\mathrm{Cd}}\right]+2\left[V_{\mathrm{Cd}} D\right]<[D]_{\mathrm{T}}<2\left[V_{\mathrm{Cd}}\right]+2\left[V_{\mathrm{Cd}} D\right] \text {. }
$$

These relations delimit the range of donor compensation. As before, at low donor concentration, a p-type conductivity is predicted, dominated by the ionized species

$$
V_{\mathrm{Cd}}^{\prime} \quad \text { or } \quad\left(V_{\mathrm{Cd}} D\right)^{\prime} .
$$

2.3 Chemical compensation. - This concept has been introduced by Canali and al. [7]. These authors assume that the compensated state is defined by the general relation

$$
[D]_{\mathrm{T}}=2\left[V_{\mathrm{Cd}}\right]_{\mathrm{T}}
$$

which replaces the neutrality equation. Free donor atoms and vacancies are considered as well as donorvacancy complexes so that

$$
\begin{aligned}
{[D]_{\mathrm{T}} } & =[D]+\left[V_{\mathrm{Cd}} D\right]+2\left[V_{\mathrm{Cd}} 2 D\right] \\
{\left[V_{\mathrm{Cd}}\right]_{\mathrm{T}} } & =\left[V_{\mathrm{Cd}}\right]+\left[V_{\mathrm{Cd}} D\right]+\left[V_{\mathrm{Cd}} 2 D\right] .
\end{aligned}
$$

The new complex introduced $\left(V_{\mathrm{Cd}} 2 D\right)$ is constituted by two donor atoms nearest neighbours of a cadmium vacancy.

The compensation condition reduces to

$$
[D]=2\left[V_{\mathrm{Cd}}\right]+\left[V_{\mathrm{Cd}} D\right] .
$$

Mass action laws relate isolated species and complexes such as

$$
\frac{\left[V_{\mathrm{Cd}} D\right]}{\left[V_{\mathrm{Cd}}\right][D]}=K_{\mathrm{p}} \sim \exp \frac{0.8(\mathrm{e} V)}{k T} .
$$

The numerical value is deduced from the energy of the bonds in compounds like $\mathrm{CdCl}_{2}$, and is not much different from the value assumed by Chern [5].

Starting from the general constraint [16] and introducing the mass action relations of the form [20] the relative concentration of the various chemical species can be computed.

On the experimental ground, time of flight measurements show that the electrical state of chlorine compensated crystals is dominated by one donor level at $E_{\mathrm{c}}-0.02 \mathrm{eV}$, associated to $D^{\circ}$ and an acceptor level at $E_{\mathrm{v}}+0.14 \mathrm{eV}$ which is related to $\left(V_{\mathrm{Cd}} D\right)$. These two species are present in equal concentrations around $10^{16} \mathrm{~cm}^{-3}$. Introducing this value in eq. (20) one deduces that $\left[V_{\mathrm{Cd}}\right]=10^{17} \mathrm{~cm}^{-3}$ at $700{ }^{\circ} \mathrm{C}$. Consequently the free cadmium vacancies should indeed dominate the compensation process if they were ionized. This point was not discussed by the authors

2.4 Complete SelF CONSISTENT MODel. - Cornet [8] has recently done numerical calculations taking into account a number of native defects and the two complexes considered by Canali and al. [7].

Electrical neutrality is written as :

$n-p=\left[D^{\bullet}\right]+\mathrm{Cd}_{\mathbf{i}}^{*}+2 \mathrm{Cd}_{\mathbf{i}}^{*}-\left[V_{\mathrm{Cd}}^{\prime}\right]-$

$$
-2\left[V_{C d}^{\prime \prime}\right]-\left[V_{C d} D\right]^{\prime} \text {. }
$$


The adopted energy level scheme is, for the acceptor levels :

$$
\begin{aligned}
E_{1}\left(V_{\mathrm{Cd}}^{\prime}\right) & =E_{\mathrm{v}}+0.35 \mathrm{eV} ; \\
E_{2}\left(V_{\mathrm{Cd}}^{\prime \prime}\right) & =E_{\mathrm{v}}+0.9 \mathrm{eV} ; \\
E_{3}\left(V_{\mathrm{Cd}} D\right) & =E_{\mathrm{v}}+0.15 \mathrm{eV} .
\end{aligned}
$$

Cornet finds that the major compensating species are $\mathrm{Cd}_{\mathrm{i}} \cdot \dot{ }$ on the donor side and $\left(V_{\mathrm{Cd}} D\right)^{\prime}$ on the acceptor side.

We shall no more discuss this model which is described in the present proceedings [9].

The main requirement in all the preceding models except the last one is the availability of ionized free vacancies in a concentration comparable to the donor content, usually in the range $10^{16}-10^{17} \mathrm{~cm}^{-3}$. With reasonnable values of the pairing constants the complex concentration is indeed always smaller than the free vacancy concentration (see $\S 2.3$ ).

This remark invites to look for simple experiments in which ionized vacancies are clearly revealed. The results of such experiments should be consistent with the requisites of the compensation models.

3. Free Cadmium vacancies in CdTe. - 3.1 HigH TEMPERATURE MEASUREMENTS. - A direct information about free cadmium vacancies can in principle be obtained from electrical measurements on undoped crystals equilibrated under a low cadmium vapour pressure.

Such measurements were carried out by Smith [10]. The results, partly summarized in figure 4 , show that

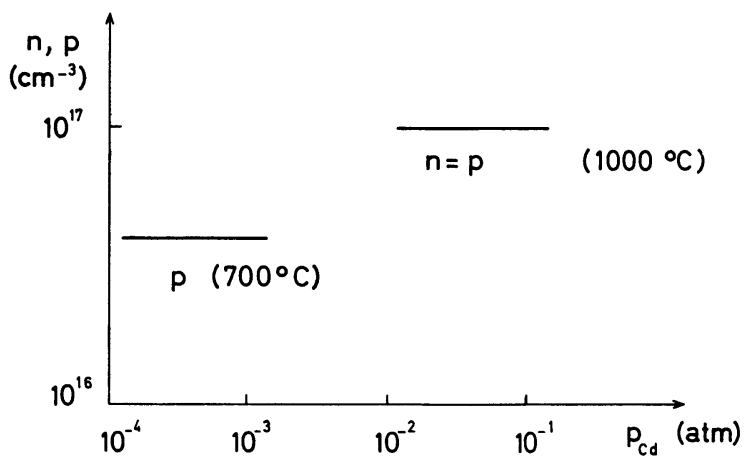

FIG. 4. - Variation of the free carrier concentrations as a function of the cadmium vapour pressure on the low pressure side (from Smith [10]).

the free carrier concentrations remain constant when the pressure is increased by a factor of ten from the tellurium saturation boundary. Obviously the electric properties of CdTe are not dominated by native defects under these conditions. At $700^{\circ} \mathrm{C}$ crystals are p-type due to residual foreign acceptors. At $1000^{\circ} \mathrm{C}$ the intrinsic range is reached.

This behaviour is quite different from the one observed on $\mathrm{ZnTe}$, in which, under similar conditions, the hole concentration varies as $p_{\mathrm{Zn}}^{-1 / 3}$ indicating the existence of a doubly ionized native defect [11].

From Smith results, one can set an upper limit on the concentration of ionized vacancies. At $1000^{\circ} \mathrm{C}$ near the tellurium saturation limit one has :

$$
\left[V_{\mathrm{Cd}}^{\prime}\right]+2\left[V_{\mathrm{Cd}}^{\prime \prime}\right] \leqslant 10^{16} \mathrm{~cm}^{-3} \text {. }
$$

Ionized tellurium insterstitials could be considered instead of cadmium vacancies but are generally thought to be minority acceptor species. The condition (22) sets a relation between the parameters of the problem $E_{1}, E_{2}$ and $V_{\mathrm{Cd}}^{x}$, which will be now examined.

3.2 Relation Between THE IONIZATION ENERGIES. - First, let us fix the neutral vacancy concentration $\left[V_{\mathrm{Cd}}^{x}\right]$, taking the values arrived at by Kroger [12]. Figure 5 shows the variation of the neutral vacancy

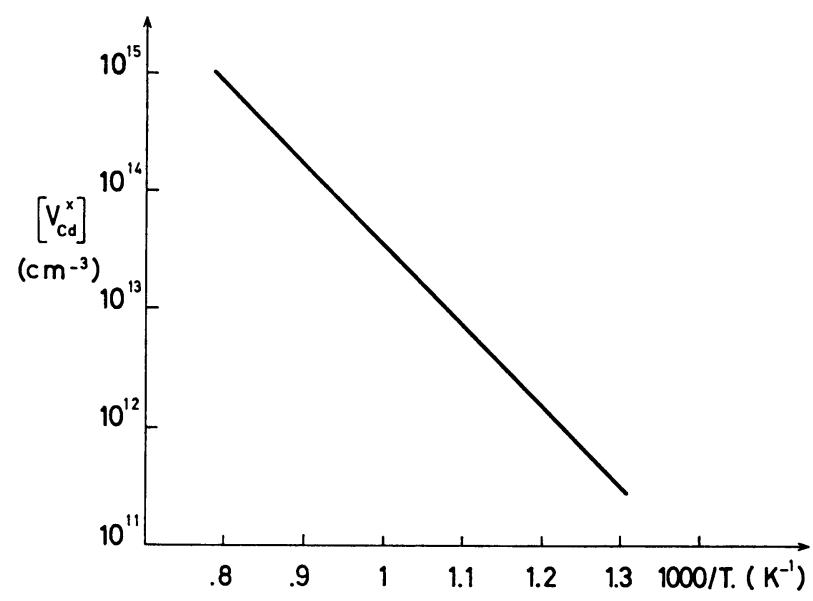

Fig. 5. - Variation of the neutral cadmium vacancy concentration at the tellurium saturation boundary, according to Kroger [12].

concentration versus temperature at the tellurium saturation boundary. Similar values are obtained in the case of $\mathrm{ZnTe}$.

The relation between $E_{1}$ and $E_{2}$ required to satisfy the high temperature condition (22) is depicted on figure 6 (full curve). The energy values are higher than usually admitted : e. g. for $E_{1}=0.44 \mathrm{eV}$, $E_{2}=0.9 \mathrm{eV}$.

If we adopt lower values for $\left[V_{\mathrm{Cd}}^{x}\right]$, for instance dividing by $10^{2}$ the values indicated on figure 5 , we obtain another relation between $E_{1}$ and $E_{2}$ (Fig. 6, dotted curve). The required energy values are then smaller : e. g. for $E_{1}=0.11 \mathrm{eV}, E_{2}=0.6 \mathrm{eV}$.

Let us remark that these energy values represent, in each case, lower limits for the two ionization energies, because they correspond to the equality in condition (22). Nevertheless, one can now ask whether compensation is possible, assuming the sets of parameters, $E_{1}, E_{2}$ and [ $V_{\mathrm{Cd}}^{x}$ ], determined as above. 


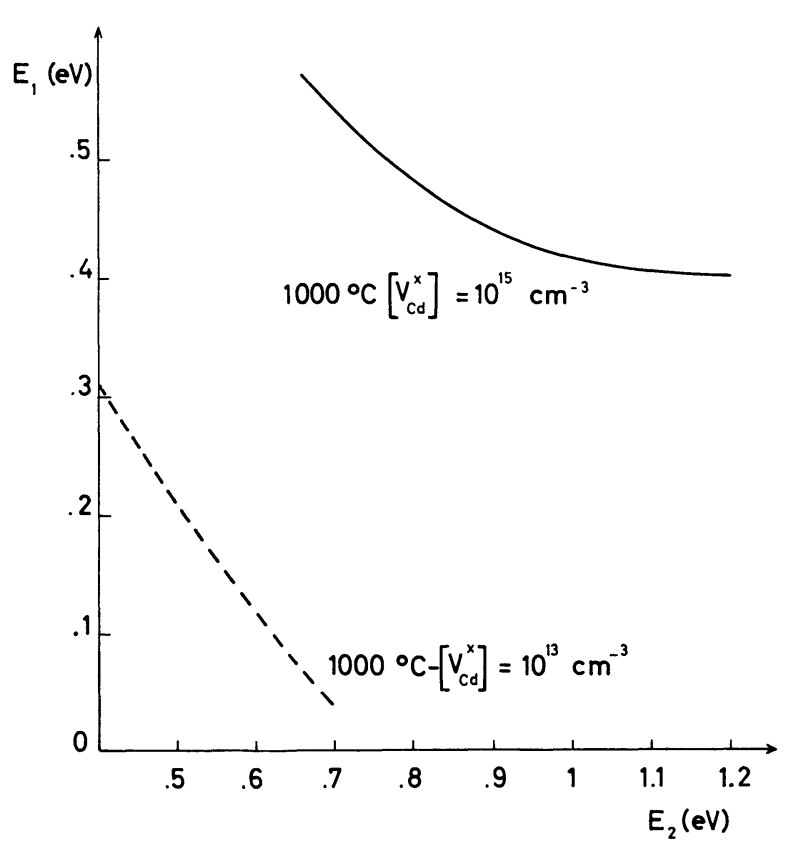

FIG. 6. - Relation between the two ionization energies of the cadmium vacancy deduced from high temperature data.

3.3 VACANCY CONCENTRATION IN PRESENCE OF DONORS. - Let us assume a donor concentration $[D]_{\mathrm{T}}=10^{17} \mathrm{~cm}^{-3}$. The concentration of the various ionized species present under vapour solid equilibrium can be computed as indicated in 2.1 , introducing the new sets of parameters.

The total vacancy concentration obtained in this way is presented on figure 7 as a function of the equilibrium temperature at the tellurium saturation boundary. The curves have been limited at $T=700^{\circ} \mathrm{C}$ which is the lowest temperature used for compensating crystals by quenching. For slowly cooled samples

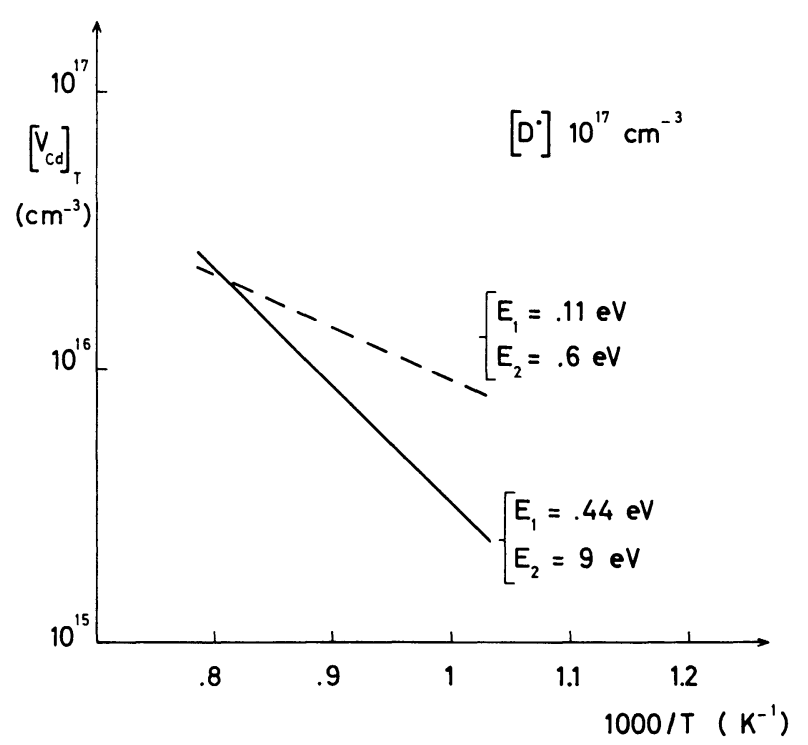

Fig. 7. - Total vacancy concentration as a function of the equilibrium temperature for $\mathrm{Te}$ saturated crystals containing $1017 \mathrm{~cm}^{-3}$ donors. lower equilibrium temperatures should be considered; this remains to be analysed although the existence of a phase equilibrium at these low temperatures is questionnable.

We conclude that, with our sets of parameters, the total concentration of vacancies is not sufficient to compensate the donor impurities.

The parameters can be modified in two ways.

i) reduce the ionization energies, which requires, to be consistent with the high temperature equilibrium data, a corresponding decrease in the neutral vacancy centration $\left[V_{\text {Cd }}^{x}\right]$.

In presence of donors, this would lead to a larger concentration of ionized vacancies and compensation could occur.

ii) increase the neutral vacancy concentration $\left[V_{\mathrm{Cd}}^{x}\right]$, and correspondingly the ionization energies. In this case the ionized vacancy concentration remains always small, even in the presence of donors, but a new process of compensation could be imagined, involving interaction of donors with neutral vacancies.

The possibility ii) seems supported be several experimental facts which give evidence of the presence of a large number of neutral defects in cadmium telluride :

- density and lattice measurements have been reported by Kiseleva [13], Kyle [14] and discussed by Mullin [15]. The results indicate a deviation from stoichiometry up to $10^{19} \mathrm{~cm}^{-3}$ at the boundaries of the existence range,

- analysis of electron mobility at low temperature performed by Caillot [16] reveal the presence of $10^{16} \mathrm{~cm}^{-3}$ neutral defects in THM crystals annealed under a medium cadmium pressure.

At room temperature such neutral defects can consist of free vacancies but also of vacancy agregates At high temperature the agregates dissociate and a larger number of isolated neutral vacancies are expected.

4. A compensation model involving neutral vacancies. - A tentative model can now be advanced, consistent with the previous deductions.

The central phenomenon is the creation of donorvacancy complexes. Formation of complexes is usually favoured by the electrostatic interaction between oppositely charged species. However trapping of vacancies without a coulombic attraction is possible at it has been proved for silicon containing Ge or Sn [17]. It can be then suggested that trapping occurs in the strain field produced around a foreign atom present on a lattice site. The complex ionized donor-neutral vacancy is subsequently stabilized by electron trapping. Such an electron trapping can be seen as due to a lowering of the vacancy energy levels, perturhed by the near ionized donor atom. 
Stable complexes are thus formed via a three particles interaction

$$
D^{\cdot}+V_{\mathrm{Cd}}^{x}+e^{-} \rightleftarrows\left(D V_{\mathrm{Cd}}\right) .
$$

The related mass action law is

$$
\frac{\left[D V_{\mathrm{Cd}}\right]}{\left[D^{\bullet}\right]\left[V_{\mathrm{Cd}}^{x}\right] n}=K_{\mathrm{c}} \text {. }
$$

The neutrality equation can be written

$$
n-p=D^{\bullet}-\left(D V_{\mathrm{Cd}}\right)^{\prime}
$$

assuming only one state of ionization for the complex $\left(D V_{\mathrm{Cd}}\right)$ (eq. (13)). The last equation becomes

$$
n-p=\frac{[D]_{\mathrm{T}}\left[1-n^{2} N_{\mathrm{v}}\left[V_{\mathrm{Cd}}^{x}\right] \frac{K_{3} K_{\mathrm{c}}}{K_{0}}\right]}{1+n\left[V_{\mathrm{Cd}}^{x}\right] K_{\mathrm{c}}\left(1+n N_{\mathrm{v}} \frac{K_{3}}{K_{0}}\right)} .
$$

The solution of this equation requires the knowledge of the various constants involved. However a distinctive property is that a unique defined solution is obtained for $\left[V_{\mathrm{Cd}}^{x}\right] \rightarrow \infty$. In particular the conductivity of the material does not increase indefinitely on the p-type side when $\left[V_{\mathrm{Cd}}^{x}\right]$ increases, at it is predicted by the classical models.

In this compensation model, the leading role is due to impurities. Vacancies come into play only to form impurity complexes which can trap electrons on deep levels and thus electrically compensate the donors.

Undoped material prepared with a Te excess is dominated by residual acceptor impurities as discussed in 3.2. In the usual compensation technique, donors, like In or $\mathrm{Cl}$ are incorporated in the cyrstals. These donors are first needed to compensate the excess foreign acceptors. The extra number of donors are in their turn compensated by forming stable complexes with vacancies according to reaction (23).

It is suggested that some of the energy levels introduced by the complexes are deep levels which stabilize the Fermi level near the midgap. Along this line the difference in conductivity type between $\mathrm{Cl}$-doped and In-doped material could be understood: the perturbation strength acting on the vacancy energy levels is stronger inside the complex $\mathrm{Cl}-V_{\mathrm{Cd}}$, the two elements being near nearest neighbours. As a result a lower energy level is expected for the acceptor $\left(D V_{\mathrm{Cd}}\right)^{\prime}$, and indeed $\mathrm{Cl}$ compensated crystals are p-type, while In compensated crystals are n-type.
5. Conclusions. - The review of present compensation models makes to appear the leading role played by ionized free cadmium vacancies.

Results of high temperature measurements are discussed which set certain limits to the concentration of ionized vacancies under specified conditions. This can be used to establish a relation between the main parameters of the problem : the two ionization energies of the vacancy and the equilibrium value of neutral vacancies.

It is shown that with accepted values of these parameters, linked by the above relation, the electrical compensation of donor impurities in the range $10^{17} \mathrm{~cm}^{-3}$ cannot be accounted for. A way to get out is to suppose a very large concentration of cadmium vacancies, and to admit the possibility of a donor-neutral vacancy interaction, stabilized by electron trapping, to form compensating complexes. Some experimental facts indeed suggest the presence of a large number of neutral defects.

From this view-point the electronic perfection of $\mathrm{Te}$ saturated $\mathrm{CdTe}$ is limited by residual and incorporated impurities. An increase in the purity of the material should lead to a decrease in the electrically active centers concentration which would be ultimately limited by the unknown concentration of ionized cadmium vacancies.

Recent experiments by Triboulet [18] seem to support this view. A given CdTe ingot was submitted to several successive THM passes. Between each operation the properties of the ingot were measured (Table I). A continuous resistivity increase is observed

TABLE I

$\begin{array}{ccc}\text { Number of } & \rho(\Omega \cdot \mathrm{cm}) & \mu_{\mathrm{p}}\left(\mathrm{cm}^{2} / \mathrm{V} \times \mathrm{s}\right) \\ \text { the passes } & 300 \mathrm{~K} & 300 \mathrm{~K} \\ \frac{-1}{1} & -\overline{380} & -33 \\ 3 & 1800 & 87 \\ 4 & 10^{5} & \end{array}$

with the number of passes. Such behaviour cannot be explained if the active acceptors are supposed to be ionized vacancies.

This experiment gives hope to obtain by extensive purification high resistivity crystals useful for nuclear radiation detectors.

Finally the problem of donor compensation is still an open question. Experiments on purer crystals are needed to precise the respective roles of ionized and neutral vacancies.

\section{References}

[1] De Nobel, Philips Res. Repts. 14 (1959) 361, 430.

[2] KROGER, F. A., The chemistry of Imperfect Crystals. North Holland, Amsterdam, Interscience, New York (1964) p. 672.

[3] Mandel, G., Phys. Rev. 134 A (1964) 1073.
[4] Triboulet, R., Marfaing, Y., Cornet, A. and Siffert, P., J. Appl. Phys. 45 (1974) 2759.

[5] Chern, S. S., Vydyanath, H. R. and Kroger, F. A., J. Sol. Stat. Chem. 14 (1975) 33. 
[6] Höschl, P., Polivka, P., Piosser, V., Sakalas, A., Czech. J. Phys. B 25 (1975) 585.

[7] Canali, C., Ottaviani, G., Bell, R. O. and Wald, F. V., J. Phys. Chem. Sol. 35 (1974) 1405.

[8] CoRnet, A., Dr. Sc. Thesis, Strasbourg, 1976.

[9] Cornet, A., Stuck, R. and Siffert, P., 2nd Int. Symp. on CdTe Strasbourg, 1976.

[10] SMITH, F. T. J., Metal. Trans. 1 (1970) 617.

[11] Thomas, D. G. and Sadowski, E. A., J. Phys. Chem. Sol. 25 (1964) 395

[12] Kroger, F. A., J. Phys. Chem. Sol. 26 (1965) 1707.
[13] Kiseleva, K. V., Klevkov, U. V., Maximovsky, S. N., Medvedey, S. A. and Senturina, N. N., Proc. Int. Symp. on CdTe, Strasbourg, 1971, p. XII (Edited by P. Siffert and A. Cornet, CRN Strasbourg).

[14] KyLE, N. R., ref. [13], p. IV.

[15] Mullin, J. B., 2nd. Int. Symp. on CdTe, Strasbourg, 1976.

[16] CaIllot, A., 2nd. Int. Symp. on CdTe, Strasbourg, 1976.

[17] Brelot, A., Radiation damage and Defects in Semicond. (The Institute of Physics) Conf. Series $n^{\circ}$ 16, p. 191 (1973).

[18] Triboulet, R., 2nd Int. Symp. on CdTe, Strasbourg, 1976. 